\title{
Commentary: Just say NO? Does nitric oxide improve myocardial protection during cardiac surgery?
}

\author{
Darrell Wu, MD, and Ravi K. Ghanta, MD
}

\footnotetext{
From the Division of Cardiothoracic Surgery, Michael E. DeBakey Department of Surgery, Baylor College of Medicine, Houston, Tex.

Disclosures: Authors have nothing to disclose with regard to commercial support.

Received for publication Oct 10, 2018; accepted for publication Oct 10, 2018; available ahead of print Nov 20 , 2018.

Address for reprints: Ravi K. Ghanta, MD, Division of Cardiothoracic Surgery, Michael E. DeBakey Department of Surgery, Baylor College of Medicine, One Baylor Plaza, MC 390, Houston, TX 77030 (E-mail: Ravi. ghanta@bcm.edu).

J Thorac Cardiovasc Surg 2019;157:2337-8

$0022-5223 / \$ 36.00$

Copyright (C) 2018 Published by Elsevier Inc. on behalf of The American Association for Thoracic Surgery

https://doi.org/10.1016/j.jtcvs.2018.10.044
}

Ischemia-reperfusion injury during cardiopulmonary bypass (CPB) is inevitable, and the quest to ameliorate this injury has been pursued for decades. In their study in this issue of the Journal, Kamenshcikov and colleagues ${ }^{1}$ have taken on this challenge, hypothesizing that nitric oxide (NO) in the cardiopulmonary bypass circuit will reduce myocardial injury during coronary artery bypass grafting (CABG) surgery. The salutary effects of NO have been the subject of intense investigation, which indeed culminated with the Nobel Prize in Medicine in $1998 .^{2}$ For adult cardiac surgery, the use of $\mathrm{NO}$ and phosphodiesterase inhibitors has primarily affected the management of pulmonary hypertension. NO, however, has multiple potential effects on cardiac myocytes, including enhancement of myocyte relaxation and inhibition of myocardial oxygen consumption. ${ }^{3}$ This is also precisely the goal of myocardial protection and cardioplegia during cardiac surgery. The use of NO during CPB has previously been evaluated in in congenital heart surgery has been shown to reduce myocardial injury and improve outcomes. ${ }^{4,5}$

Kamenshchikov and colleagues ${ }^{1}$ present a singleinstitution prospective study of $60 \mathrm{CABG}$ patients randomly allocated to receive $40 \mathrm{ppm}$ of NO versus control. Myocardial injury was assessed with biomarkers (cardiac troponin I, creatine kinase isoenzyme MB) at 6 and 24 hours postoperatively. They found that both cardiac troponin I and creatine kinase isoenzyme MB were lower in the NOtreated group. In addition, vasoactive inotropic support scores were calculated within the first 48 hours of surgery. They found that NO-treated patients had decreased vasoactive inotrope requirements relative to controls. There are 3 main points that bear mentioning when considering this study. First, this study is limited by a small cohort of lowrisk patients undergoing $\mathrm{CABG}$, making it difficult to draw any strong conclusions. It is unclear whether $\mathrm{CABG}$ represents the best patient cohort to evaluate the potential benefit of NO. Overall, CABG has become a low-risk

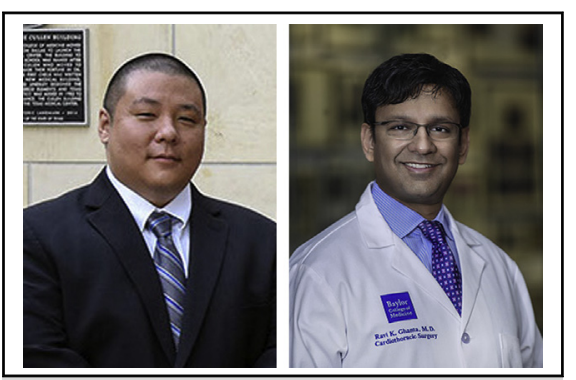

Darrell Wu, MD, and Ravi K. Ghanta, MD

\section{Central Message}

Nitric oxide plays a critical role in myocardial ischemia-reperfusion injury and may further augment myocardial protection strategies related to cardiopulmonary bypass.

See Article page 2328. cardiac surgery operation, especially for patients with normal ventricular function undergoing an elective operation. A more salient clinical benefit might be detected in patients with ventricular dysfunction, recent myocardial infarction, incomplete revascularization, or more complex operations. Second, it is unclear whether cardiac injury biomarkers are independently prognostic of clinical outcomes. Beller and colleagues ${ }^{6}$ found that peak troponin does not influence CABG outcomes after myocardial infarction. Furthermore, there are many randomized control trials demonstrating decreased biomarkers of injury in off-pump CABG, but little change in outcome. Third, the systemic effects of NO should be considered. These systemic effects may prove to have a benefit independent of myocardial injury. In a study by Cecchia and colleagues ${ }^{4}$ in pediatric patients undergoing tetralogy of Fallot repair, the addition of NO to the CPB circuit led to improved fluid balance. ${ }^{4}$ Furthermore, in a study by Lei and colleagues, ${ }^{7}$ the addition of $\mathrm{NO}$ to the $\mathrm{CPB}$ circuit in patients undergoing mitral valve replacement led to less acute kidney injury. ${ }^{7}$ These findings suggest that systemic effects of NO may be beneficial.

This pilot study shows that administration of NO during CPB is safe, feasible, and economical. Further randomized trials and larger investigational studies are needed. Future studies should be performed in a cohort of higher risk patients, with outcomes that assess myocardial protection and systemic benefits. 


\section{References}

1. Kamenshchikov NO, Mandel IA, Podoksenov YK, Svirko YS, Lomivorotov VV, Mikheev SL, et al. Nitric oxide provides myocardial protection when added to the cardiopulmonary bypass circuit during cardiac surgery: randomized trial. J Thorac Cardiovasc Surg. 2019;157:2328-36.

2. Mitka M. 1998 NObel Prize winners are announced: three discoverers of nitric oxide activity. JAMA. 1998;280:1648.

3. Heusch G, Post H, Michel MC, Kelm M, Schulz R. Endogenous nitric oxide and myocardial adaptation to ischemia. Circ Res. 2000;87:146-52.

4. Checchia PA, Bronicki RA, Muenzer JT, Dixon D, Raithel S, Gandhi SK, et al. Nitric oxide delivery during cardiopulmonary bypass reduces postoperative morbidity in children — a randomized trial. J Thorac Cardiovasc Surg. 2013; 146:530-6.

5. James C, Millar J, Horton S, Brizard C, Molesworth C, Butt W. Nitric oxide administration during paediatric cardiopulmonary bypass: a randomised controlled trial. Intensive Care Med. 2016;42:1744-52.

6. Beller JP, Hawkins RB, Mehaffey JH, LaPar DJ, Kron IL, Yarboro LT, et al. Does preoperative troponin level impact outcomes after coronary artery bypass grafting? Ann Thorac Surg. 2018;106:46-51.

7. Lei C, Berra L, Rezoagli E, Yu B, Dong H, Yu S, et al. Nitric oxide decreases acute kidney injury and stage 3 chronic kidney disease after cardiac surgery. Am J Respir Crit Care Med. June 22, 2018 [Epub ahead of print]. 